\title{
Coming in, or going out? Measuring the effect of discourse factors on perspective prominence
}

\author{
Carolyn Jane Anderson*
}

\begin{abstract}
Although perspectival expressions are a diverse group, they share a common property: their meanings depend on the perspective of a discourse-given individual whose identity is under-specified. This paper investigates how perspective holder prominence is determined through a series of forced choice experiments on American English motion verbs exploring a number of discourse factors: definiteness, mention order, topicality, and subjecthood. The results suggest that both global and local prominence effects play a role in determining how perspectival motion verbs are interpreted.
\end{abstract}

Keywords. perspective; discourse prominence; psycholinguistics

1. Introduction. Perspective plays a role in many linguistic phenomena, including predicates of personal taste, epithets, expressives, motion verbs like come, and discourse environments like Free Indirect Discourse. Despite the diversity of perspectival expressions, they share a common property: their meanings depend on the perspective of a discourse-given individual whose identity is underspecified. For instance, in (1), tasty may be anchored to the speaker or to the attitude holder.

(1) Susan says that the tasty pumpkin pie is almost ready to eat.

a. Speaker-oriented: It was nice of her to make it when she doesn't even like pie.

b. Attitude-holder-oriented: I'm not a fan of pie, but she thinks it's the best part of fall.

The choice of perspective rests on the discourse prominence of the characters: certain characters hold perspectives that are more accessible than others. While the factors that determine discourse prominence have been much discussed in the context of pronominalization (Chafe 1976, Hobbs 1979, Kehler 2002, Kehler et al. 2008, Kehler \& Rohde 2013), there is comparatively little work on what affects the prominence of various potential perspective holders in a discourse.

This paper contributes to the growing body of work on perspective prominence (Harris 2012, Kaiser \& Lee 2017a,b, Hinterwimmer 2019) by providing experimental data on a relatively underexplored class of perspectival expressions: motion verbs like come and go.

I present a series of experiments that explore how discourse factors impact the prominence of perspective holders for come in English. In Experiment 1, I find that both subjecthood and topicality affect perspective prominence. Experiments 2 and 3 replicate and delve into these findings: Experiment 2 compares two kinds of topicality, and Experiment 3 compares two kinds of subjecthood. The results suggest that global effects like topicality and local effects like subjecthood both play a role in determining who the perspective holder is for perspectival motion verbs in English.

2. Perspectival expressions. Perspectival expressions are interpreted relative to the point-of-view of a particular individual, referred to as the perspective holder. ${ }^{1}$ For instance, the motion verb

\footnotetext{
*Many thanks to Daniel Altshuler, Brian Dillon, Elsi Kaiser, Carina Bolaños Lewen, and the participants and reviewers of Experiments in Linguistic Meaning 1 for their questions and suggestions. Authors: Carolyn Jane Anderson, University of Massachusetts, Amherst (carolynander@umass.edu).

${ }^{1}$ In the literature on some perspectival expressions, the term judge is used; I use perspective holder for consistency.
} 
come requires a perspective holder to be located at the destination of motion (2). ${ }^{2}$

(2) Context: Susie and Suzy are chatting in Boston.

a. Suzy: Taylor Swift is \{coming/\#going $\}$ to Boston.

b. Suzy: Taylor Swift is $\{\#$ coming/going $\}$ to L.A.

The perspective holder plays a critical role in determining the truth conditions of perspectival expressions. A number of semantic treatments have been proposed, which fall into three broad categories: indexical approaches (Oshima 2006a,b, Korotkova 2016, Sudo 2018); binding approaches, which treat the perspective holder as a variable bound by an antecedent (Pearson 2013, Nishigauchi 2014, Charnavel 2018, Sundaresan 2018, Charnavel 2020); and anaphoric approaches (Barlew 2017, Roberts 2020). Figure 1 shows the semantics of come in each kind of analysis.

Indexical analysis (Oshima 2006b): $[[\text { come }]]^{C, g}=\lambda x . \exists e . \exists y \in C_{p s} \cdot \operatorname{MOVE}(e) \wedge \operatorname{DEST}(e, x) \wedge$ $x=\operatorname{LOC}(y))$, where $C_{p s}$ is context parameter $C$ 's set of contextually relevant perspectives.

Logophoric binding analysis (Charnavel 2020): $\left[\left[\operatorname{come}_{i}\right]\right]^{C, g}=\lambda x \cdot \exists e \cdot \operatorname{MOVE}(e) \wedge \operatorname{DEST}(e, x) \wedge$ $x=\operatorname{LOC}\left(l_{i}\right)$, where $l_{i}$ is bound by the subject of a logophoric operator $\mathrm{OP}_{\mathrm{LOG}}$.

Anaphoric analysis (Barlew 2017): $[[\text { come }]]^{C, g}=\lambda x \cdot \exists e \cdot \operatorname{MOVE}(e) \wedge \operatorname{DEST}(e, x) \wedge x=\operatorname{LOC}(p)$, where $p$ is a prominent perspective holder in the Common Ground.

Figure 1: Three semantic analyses for come

Although these approaches propose different ways of valuing the perspectival variable, each assumes a role for pragmatics. In Oshima (2006b)'s approach, the context parameter contains a contextually determined set of perspective holders; in Charnavel (2020)'s approach, the perspectival variable is bound by a logophoric pronoun whose value is contextually determined; and in Barlew (2017)'s approach, the perspectival variable is resolved by the discourse context. The issue of perspective prominence is therefore important regardless of the analysis that is adopted.

3. Perspective prominence. The perspective holder can't be just any individual. This is shown in (2-b): although L.A. is full of people, they cannot serve as perspective holders for come. To be a perspective holder, an individual must hold a discourse prominent perspective:

(3) Discourse prominence (Heusinger \& Schumacher 2019): a relational property that (1) singles out members of a discourse-given set, (2) shifts as the discourse unfolds, and (3) licenses special access to, or more operations on, prominent elements than competitors.

For perspectival expressions, the idea is that there is a ranked set of discourse-given perspectives (or individuals with perspectives), and higher ranked perspectives are more accessible. This accounts for the contrast in (2): in (2-a), the speaker and listener hold discourse-important perspectives in Boston, but in (2-b), there is no perspective in L.A. prominent enough to license come.

\footnotetext{
${ }^{2}$ Note that the set of licit perspective holders varies by language; English is a useful language for exploring perspective prominence because it allows a large set. See Nakazawa (2007) and Barlew (2017) for more discussion.
} 
In conversational contexts like (2), it is intuitive that the speaker and listener perspectives are prominent, since they are always relevant to the discussion. But how is discourse prominence determined in third-person narratives, where there may not be any overt conversation participants?

One idea is that prominence is determined by how closely related each individual is to the topic of the discourse. This is a global notion of prominence: certain individuals are more important to the discourse theme and have prominence throughout the discourse. ${ }^{3}$

Another possibility is that prominence is determined by local effects: features of the grammatical environment in which the perspectival expression occurs. For example, filling certain thematic or syntactic roles may temporarily increase the prominence of an individual's perspective. The global and local views of discourse prominence are not necessarily in opposition, since it is also possible that multiple factors affect perspective prominence.

3.1. Previous WORK ON PERSPECTIVE PROMINENCE. Both global and local factors have been explored in the growing body of work on perspective prominence. Early work sought to evaluate the relative prevalence of subject- and attitude holder-oriented readings (Harris \& Potts 2009, Harris 2012, Kaiser 2015). Attitude reports are one common environment for global and local prominence to conflict, because speaker perspectives are globally prominent, while attitude holder perspectives are locally prominent in the environment of the attitude report. More recent work has begun to investigate perspective prominence in third-person narrative contexts, focusing on two main perspectival phenomena: Free Indirect Discourse and predicates of personal taste.

Kaiser has explored the factors that affect how predicates of personal taste are interpreted in a series of perspective-judgment studies (Kaiser \& Lee 2017a,b, Kaiser 2020). Her results suggest that individuals who fill an Experiencer thematic role (Kaiser \& Lee 2017b,a) or who are the source of information (i.e. subject of told or object of heard from) (Kaiser 2020) are preferred perspective holders for predicates of personal taste. These are both local prominence effects. However, she interprets her findings as support for an Experiencer argument in the semantics of predicates of personal taste (Bylinina 2014, McNally \& Stojanovic 2017); if this is the case, they may not generalize to perspectival expressions that do not have a grammatically represented Experiencer.

For Free Indirect Discourse, ${ }^{4}$ both local and global effects seem to play a role. Hinterwimmer (2019) proposes that two factors affect the accessibility of perspectives for Free Indirect Discourse: topicality and thematic roles. He finds that individuals who fill an Experiencer thematic role in a preceding sentence, regardless of whether they are the subject, are more likely to be interpreted as Free Indirect Discourse perspective holders. He also finds that individuals introduced early in a discourse are more likely to be perspective holders, evidence of global prominence. Meuser et al. (2020) explored these factors experimentally in a series of acceptability judgment and eye-tracking studies. Although the eye-tracking results did not show any reliable effects, there was a numerical preference for the perspectives of subjects and of named characters.

To summarize, the existing literature on perspectival expressions suggests that both global and local prominence play a role in determining the perspective holder in third-person contexts. On the

\footnotetext{
${ }^{3}$ Global prominence has been developed in the context of Centering Theory (Chafe 1976), which posits a mechanism for tracking the single most prominent individual (center) at a given point in the discourse and proposes that shifting this center decreases discourse coherence. See Poesio et al. (2004) for an overview of different variations.

${ }^{4}$ A mixed-perspective discourse environment. See Banfield (1982), Eckardt (2014) for a description.
} 
one hand, features of the local grammatical context like subjecthood and thematic roles affect the interpretation of Free Indirect Discourse and predicates of personal taste. On the other hand, the work on Free Indirect Discourse suggests that global prominence is also important, since the order and way in which the individuals were introduced affected their prominence.

Although these findings may not generalize to other perspectival expressions, I take them as useful hints about the discourse factors that may determine perspective prominence. In the following sections, I present a series of experiments that explore the impact of these discourse factors on the interpretation of another class of perspectival expressions: perspectival motion verbs.

4. Experiment 1. Experiment 1 is a come/go forced choice task measuring the impact of three potential determinants of perspective prominence: subjecthood, definiteness, and mention order. ${ }^{5}$

The forced choice paradigm makes use of the fact that the subject of come generally cannot be its perspective holder, since a person cannot be at a destination and in motion simultaneously (Barlew 2017). ${ }^{6}$ In a discourse with two characters, we can therefore measure the prominence of one character's perspective by using the other character as the subject of the motion verb. If come is used, this indicates that the non-subject character's perspective is prominent; otherwise, go will be used. Thus, the rate of come versus go selection is a measure of perspective prominence.

4.1. Method. The impact of discourse factors on perspective prominence was measured in a come/go forced choice task. Participants read three-sentence narratives and selected come or go for a missing word in the last sentence. Figure 2 shows an example item. Three discourse factors were manipulated: mention order, definiteness, and subjecthood.

1 Definite: Larry purchased a sofa for the set of the new play.

Indefinite: A stage manager purchased a sofa for the set of the new play.

2 A Subject: He got a $10 \%$ discount on it from a salesclerk.

B Subject: A salesclerk gave him a $10 \%$ discount on it.

3 A Perspective: When he $\{$ came/went $\}$ to deliver it, he got free tickets for the show.

B Perspective: When he $\underline{\{\text { came/went }\}}$ to pick it up, he gave him free tickets for the show.

Figure 2: Experiment 1 example item

Mention order The impact of mention order was measured by comparing the come selection rate for Person A and B. In each narrative, Person A was introduced in the first sentence and Person B was introduced in the second sentence.

Definiteness The impact of definiteness was measured by manipulating whether or not Person A was introduced by name in the first sentence. Person B was not named in either condition.

Subjecthood The impact of subjecthood was measured by manipulating the argument structure of the second sentence. In the A Subject condition, Person A was the subject, while in the B

\footnotetext{
${ }^{5}$ All three experiments were preregistered through the Open Science Foundation: https://osf . io/qmc $7 t$.

${ }^{6}$ There are exceptions: if a past motion event is being described and the speaker is currently located at the destination of motion, their perspective can be used to anchor come.
} 
Subject condition, Person B was the subject.

4.1.1. PARTICIPANTS. Monolingual American English-speaking participants $(n=64)$ were recruited through Prolific. Data from participants $(n=4)$ who failed to achieve $80 \%$ on the attention check items or responded incoherently to one of the two bot check questions was excluded.

4.1.2. MATERIAls. All items consisted of three-sentence narratives about two characters. Participants were asked to choose between two words to fill in the blank in the third sentence.

32 three-sentence narratives were constructed. There were 8 conditions, created by manipulating (1) whether Person A, the discourse-first individual, was named; (2) whether Person A or B was the subject of the second sentence; and (3) whether the subject of the motion verb was Person A or B. The third sentence serves to disambiguate the perspective holder: when its subject is Person A, the rate of come selection measures the prominence of Person B's perspective.

Two kinds of fillers and two kinds of attention check questions were used (Figure 3). The attention check items involved negative polarity item licensing and modals; participants who failed to achieve $80 \%$ accuracy on them were excluded.

Easy: One of the students in the class hadn't turned in his homework. Ms. Morris frowned and thought about what to do. After school, she called his mother to $\{$ tell / fail $\}$ her.

Hard: Jenny was getting dressed for a hike. As she was putting them on, the knee of her jeans ripped. She shrugged and threw them $\{$ on / out $\}$.

NPI: Susan was throwing a party on Thursday. She had invited a dozen people, but the forecast predicted snow. Kevin \{doubted / thought that anyone would come.

Modal: Emma was a vetinarian. She heard that one of her neighbors was adopting a cat. Emma told him that he $\{$ should / would $\}$ get the cat micro-chipped.

Figure 3: Example fillers

4.1.3. Procedure. Participants saw 4 items in each of 8 conditions, presented using a Latin Square design. Participants also saw 24 filler and attention check items, for a total of 56 items. At the end, participants completed a questionnaire with demographic and bot check questions.

4.2. Regression AnALYSis. Two mixed-effects logistic regression models were fitted to the response data. The pre-registered model included three fixed effects, Perspective, Subjecthood, and Definiteness, and their interactions. A post-hoc model was used to explore the interaction between Definiteness and Perspective; it included five fixed effects: Perspective, Subject, Perspective*Subject, Definiteness nested in Perspective A (AxName), and Definiteness nested in Perspective B (BxName). Sum contrast coding and the maximal random effects structure were used.

4.3. RESULTS. All three manipulated factors (being named, being the first-mentioned individual, and being the subject) were predicted to increase the prominence of a perspective holder, resulting in higher rates of come selection (Table 1). As Figure 4 shows, the differences in rates of come selection between the Person A and Person B perspective conditions narrows as the discourse conditions shift from favoring Person A to Person B. However, the three explored discourse factors 
influence the selection of the perspective holder to differing degrees.

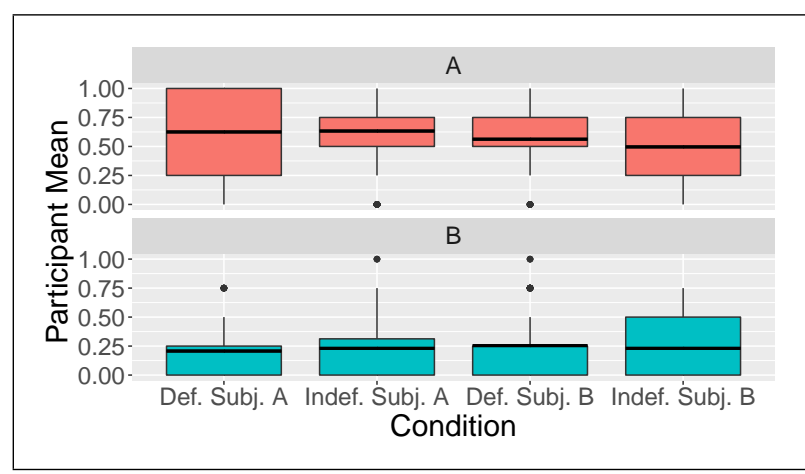

Figure 4: Experiment 1 means by condition

\begin{tabular}{|llll|}
\hline Persp. & A & B & come $[95 \%$ CI $]$ \\
\hline A & Name & Ob & $62 \%[53 ; 71]$ \\
& & Sub & $56 \%[49 ; 62]$ \\
& Anon & Ob & $63 \%[55 ; 71]$ \\
& & Sub & $50 \%[41 ; 58]$ \\
B & Name & Ob & $21 \%[16 ; 26]$ \\
& & Sub & $26 \%[20 ; 32]$ \\
& Anon & Ob & $23 \%[17 ; 30]$ \\
& & Sub & $23 \%[17 ; 30]$ \\
\hline
\end{tabular}

Table 1: Experiment 1 mean rate of come selection

The effect of mention order was strongest: in all conditions, the mean rate of come responses was higher for Person A's perspective than Person B's. As Table 2 shows, the effect of mention order was significant in both models, and switching perspectives from Person B to Person A was estimated to increase the rate of come responses to a greater extent than subjecthood or definiteness.

\begin{tabular}{|llll|}
\hline Fixed effect $(n=2048)$ & $\widehat{\beta}$ & $z$ & $p$ \\
\hline (Intercept) & $-0.59(+/-0.17)$ & -3.5 & $<\mathbf{0 . 0 0 1}$ \\
A Perspective & $1.02(+/-0.14)$ & 7.1 & $<\mathbf{0 . 0 0 0 0 1}$ \\
A Subject & $0.10(+/-0.06)$ & 1.8 & 0.07 \\
A Definiteness & $0.04(+/-0.06)$ & 0.7 & 0.50 \\
Perspective*Subject & $0.19(+/-0.06)$ & 3.4 & $<\mathbf{0 . 0 0 1}$ \\
Perspective*Definiteness & $0.04(+/-0.06)$ & 0.7 & 0.51 \\
\hline (Intercept) & $-0.59(+/-0.17)$ & -3.5 & $\mathbf{0 . 0 0 0 4}$ \\
A Perspective & $1.0(+/-0.14)$ & 7.1 & $<\mathbf{0 . 0 0 0 0 1}$ \\
Definiteness & $0.04(+/-0.06)$ & 0.68 & 0.50 \\
AxSubject & $0.29(+/-0.07)$ & 3.9 & $\mathbf{0 . 0 0 0 1}$ \\
BxSubject & $-0.09(+/-0.08)$ & -1.1 & 0.29 \\
Perspective*Definiteness & $0.04(+/-0.06)$ & 0.66 & 0.51 \\
\hline
\end{tabular}

Table 2: Experiment 1 regression analyses, interaction (top) and nested (bottom) models

There was also a reliable interaction between Subjecthood and Perspective $(p<0.001)$. The nested mixed-effects model found that Person A subjecthood had a significant positive effect on come response rates for Person A's perspective $(p<0.001)$, but did not find a significant effect on come response rates for Person B's perspective.

Neither the main effect of Definiteness nor its interaction with Perspective was significant, although a numerical trend is observable in Figure 4.

4.4. Discussion. The results of Experiment 1 support a role for both local and global prominence in determining the perspective holder of come. The strongest observed effect was that of mention order: Person A's perspective was more prominent than Person B's in all conditions. 
Mention order is a correlate of global prominence: a character who is mentioned early is more likely to be the topic of the discourse. A local prominence effect was also observed: subjecthood had a reliable, though weaker effect on perspective prominence.

Although the results of Experiment 1 suggest that both global and local prominence are in play, it leaves open several questions about the source of these effects. Unlike paradigms from previous work, the Experiment 1 paradigm did not distinguish between argument structure and thematic roles, which means that the observed subjecthood effect could also arise from a correlation between thematic roles and subjecthood. The observed effect of mention order might also have several causes: is Person A's perspective more prominent because they are mentioned earlier, or because by appearing early, they are more closely associated with the discourse theme? These factors were conflated in Experiment 1: in the Figure 2 stimulus, for instance, the stage manager character is both mentioned first and more closely related to the discourse topic.

The design in Experiment 1 also had a potential pronominalization confound. Because prominence drives pronominalization, a character who is referred to by a pronoun might be inferred to be more prominent. In Experiment 1, Person A was referred to with a pronoun in the second sentence to improve the naturalness of the narratives. However, this may have inadvertently increased the prominence of that character for reasons unrelated to mention order.

Experiment 2 seeks to address these last two points with an updated experimental paradigm.

5. Experiment 2. Experiment 2 explores the effect of subjecthood and two indicators of topicality: mention order and relation to the theme of the discourse. Similar to Experiment 1, the prominence of characters' perspectives was measured in a come/go forced choice task.

5.1. Method. As in Experiment 1, participants read three-sentence narratives and selected come or go for a missing word in the last sentence. Three discourse factors were manipulated: mention order, relation to the theme of the discourse, and subjecthood. Figure 5 shows an example item.

1 Mention: Freshman Drew was struggling with his computer science homework.

Theme: Computer Science is one of the most difficult subjects for freshmen.

2 A Subject: Drew asked an older student Sandra for help with the class.

B Subject: An older student Sandra offered to tutor Drew.

3 A Perspective: When she $\{$ came/went $\}$ to his dorm, they made a plan for how to study. B Perspective: When he $\underline{\text { came/went }\}}$ to her dorm, they made a plan for how to study.

Figure 5: Experiment 2 example item

Relation to theme As in Experiment 1, each narrative involved two characters, A and B. In this experiment, the first sentence set up a topic for the discourse more closely associated with A. For instance, in Figure 5, the first sentence frames the narrative around the challenges freshmen face.

Mention order The impact of mention order was measured by manipulating whether or not Person A was introduced in the first sentence. In the Mention condition, Person A was mentioned in the first sentence, while in the Theme condition, neither character was. 
Subjecthood The impact of subjecthood was measured by manipulating the argument structure of the second sentence. In the A Subject condition, Person A was the subject, while in the B Subject condition, Person B was. The other character was an object of the verb or a prepositional phrase.

5.1.1. PARTICIPANTS. Monolingual American English-speaking participants $(n=80)$ were recruited through Prolific. The data from participants $(n=15)$ who failed to achieve $80 \%$ on the attention check items or responded incoherently to a bot check question was excluded.

5.1.2. MATERIALS. As in Experiment 1, items consisted of three-sentence narratives about two characters. 32 narratives were constructed. There were 8 conditions, created by manipulating (1) whether Person A was introduced in the first sentence; (2) whether the subject of the second sentence was Person A or B; and (3) whether the subject of the motion verb was Person A or B. Unlike in Experiment 1, both characters were mentioned by name in all narratives. In addition, the use of pronouns in the second sentence was avoided. As before, the prominence of a character's perspective was measured as the rate of come selection.

5.1.3. Procedure. Participants saw 4 items in each of 8 conditions, presented using a Latin Square design. Participants also saw the 24 filler and attention check items from Experiment 1, for a total of 56 items. At the end, participants answered demographic and bot check questions.

5.2. REgRESSION ANALYSis. Two mixed-effects logistic regression models were fitted to the response data. The pre-registered model included three fixed effects: Perspective, Subjecthood, and Theme, and their interactions. A post-hoc nested model was used to explore the interaction effects. It included five fixed effects: Perspective, Subjecthood nested in Perspective A, Subjecthood nested in Perspective B, Theme nested in Perspective A, and Theme nested in Perspective B. Sum contrast coding and the maximal random effects structure were used.

5.3. RESUlts. The results of Experiment 2 are shown in Table 3. They support a role for all three discourse factors explored. As Figure 6 shows, as subjecthood and mention order are manipulated, the rates of come selection increase for Perspective B and decrease for Perspective A.

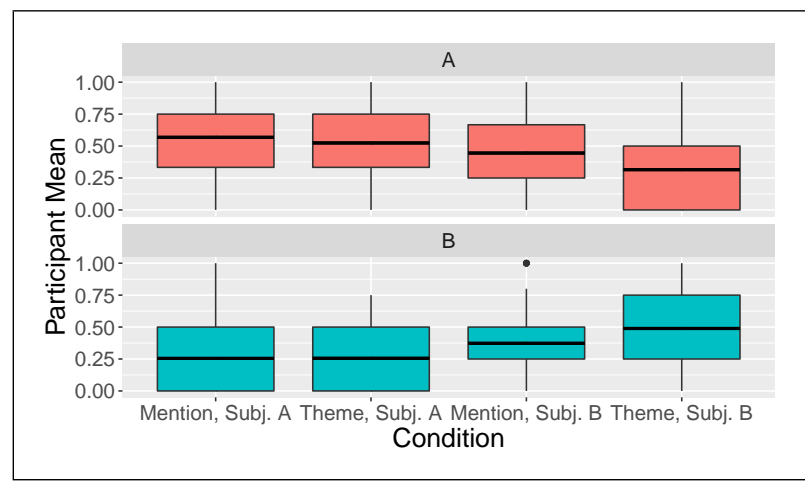

Figure 6: Experiment 2 means by condition

\begin{tabular}{|llll|}
\hline Persp. & A & B & come $[95 \%$ CI $]$ \\
\hline A & Mention & Ob & $45 \%[41 ; 48]$ \\
& & Sub & $57 \%[54 ; 60]$ \\
& Theme & Ob & $32 \%[29 ; 35]$ \\
B & & Sub & $52 \%[50 ; 55]$ \\
& Mention & Ob & $25 \%[23 ; 38]$ \\
& Theme & Ob & $37 \%[35 ; 40]$ \\
& & Sub & $49 \%[23 ; 28]$ \\
& &
\end{tabular}

Table 3: Experiment 2 mean rate of come selection

As in Experiment 1, there was a general preference for Perspective A, indicating that being 
related to the theme of the discourse increased the prominence of Person A's perspective. As Table 4 shows, the observed effect of Perspective was significant in the mixed-effects model $(p<0.001)$.

\begin{tabular}{|llll|}
\hline Fixed effect $(n=2560)$ & $\widehat{\beta}$ & $z$ & $p$ \\
\hline (Intercept) & $-0.48(+/-0.13)$ & -3.5 & 0.0004 \\
A Perspective & $0.3(+/-0.08)$ & 3.8 & $\mathbf{0 . 0 0 0 1}$ \\
A Subject & $-0.02(+/-0.05)$ & -0.54 & 0.59 \\
Theme & $0.03(+/-0.05)$ & 0.52 & 0.60 \\
A Perspective*Subject & $0.43(+/-0.05)$ & 9.5 & $<\mathbf{0 . 0 0 0 0 1}$ \\
A Perspective*Theme & $0.18(+/-0.05)$ & 4.1 & $<\mathbf{0 . 0 0 0 0 1}$ \\
\hline (Intercept) & $-0.51(+/-0.14)$ & -3.6 & 0.0004 \\
A Perspective & $0.33(+/-0.08)$ & 3.9 & $<\mathbf{0 . 0 0 0 0 1}$ \\
AxA Subject & $0.42(+/-0.08)$ & 5.0 & $<\mathbf{0 . 0 0 0 0 1}$ \\
BxA Subject & $-0.48(+/-0.1)$ & -5.0 & $<\mathbf{0 . 0 0 0 0 1}$ \\
AxTheme & $0.22(+/-0.07)$ & 3.1 & $\mathbf{0 . 0 0 2}$ \\
BxTheme & $-0.17(+/-0.08)$ & -2.0 & $\mathbf{0 . 0 4}$ \\
\hline
\end{tabular}

Table 4: Experiment 2 regression analyses, interaction (top) and nested (bottom) models

A strong effect of subjecthood was also observed: within each Mention/Theme condition, come selection increased when the perspective holder was the subject of the second sentence. In the Theme B Subject condition, unlike all other conditions, the mean come rate was higher for Person B's perspective than A's. The interaction of Perspective and Subject was significant $(p<0.00001)$. In the nested model (Table 4), both nested effects of Subject were significant ( $p<0.00001$ ), but in opposite directions: Person A having subjecthood increased the rate of come selection when A was the perspective holder, but decreased it when B was the perspective holder.

The results also suggest that mention order has an effect beyond thematic relation: come selection rates were higher for Perspective A when Person A was introduced in the first sentence. The interaction between Perspective and Theme/Mention was significant $(p<0.00001)$, and in the nested model, there were significant effects of Theme for both levels of Perspective, again in different directions: introducing Person A in the first sentence increased the rate of come selections for Perspective A $(p<0.01)$, while decreasing it for Perspective B $(p<0.05)$. However, the effect for Perspective B was weak when B was not the second sentence's subject.

5.4. Discussion. The results of Experiment 2 support the hypothesis that both global and local prominence factors affect perspective holder selection for come. This is seen most clearly in the Theme B Subject condition. Although Person A's perspective was generally preferred due to its global prominence, when this was weakened by removing the mention order effect, the local prominence granted to Person B by its subjecthood in the second sentence was enough to overcome A's global prominence and produce higher rates of come selection for B's perspective.

In addition, the data provide a more nuanced look into the global prominence effect: both mention order and relation to the theme of the discourse increase perspective prominence. In reality, the effect of relation to the theme may be stronger than what was observed: some Theme narratives may have failed to associate only Person A with the theme, since it was challenging to do this and preserve discourse coherence. 
6. Experiment 3. Experiment 3 explores the subjecthood effect observed in the previous two experiments by comparing two kinds of subject environments. Since Hinterwimmer (2019) posits that sentience with respect to a preceding eventuality influences prominence, we might expect subjects of attitude verbs to receive even larger boosts in prominence than other subjects. ${ }^{7}$ Experiment 3 explores this hypothesis by comparing the prominence of subjects of attitude verbs with subjects of verbs with Agent/Patient thematic roles.

6.1. Method. As before, the prominence of characters' perspectives was measured in a come/go forced choice task. Participants read three-sentence narratives and selected a missing word in the last sentence. Three discourse factors were manipulated: relation of the character to the theme of the discourse, the subject of the second sentence, and whether the second sentence contained an attitude verb or an verb with Agent/Patient thematic roles. Figure 7 shows an example item.

1 Being a bus driver requires a lot of patience since children can be careless.

2 A Attitude Subject: Sharon was annoyed to find fifth-grader Nick's lunch on one of the seats in her bus.

A A/P Subject: Sharon found fifth-grader Nick's lunch on one of the seats in her bus. B Attitude Subject: Fifth-grader Nick regretted leaving his lunch on one of the seats in Sharon's bus.

B A/P Subject: Fifth-grader Nick had left his lunch on one of the seats in Sharon's bus.

3 A Perspective: When he $\{$ came/went $\}$ to pick it up, he said he was sorry.

B Perspective: When she $\{$ came/went $\}$ to pick him up, she scolded him.

Figure 7: Experiment 3 example item

Relation to theme As in the Experiment 2 Theme condition, each narrative began with a thematic first sentence that was more closely related to Person A than Person B.

Subjecthood As in the previous two experiments, the impact of subjecthood was measured by manipulating whether Person A or Person B was the subject of the second sentence.

Attitude holder The impact of being an attitude holder was manipulated within the second sentence as well. In the A/P condition, the matrix verb was one with Agent/Patient thematic roles. In the Attitude condition, the matrix verb was an attitude predicate. The subject of the embedded verb was always the same as the subject of the attitude verb.

6.1.1. PARTICIPANTS. Monolingual American English-speaking participants $(n=80)$ were recruited through Prolific. The data from participants $(n=9)$ who failed to achieve $80 \%$ on the attention check items or who gave an incoherent response to one of the two free response bot check questions in the debriefing questionnaire was excluded.

6.1.2. MATERiAls. The Theme condition stimuli from Experiment 2 were adapted for this experiment. 32 three-sentence narratives were constructed. There were 8 conditions, created by

\footnotetext{
${ }^{7}$ Roberts (2020) proposes that attitude verbs introduce attitude holder perspectives into the discourse context.
} 
manipulating (1) the subject of the second sentence; (2) whether the second sentence contained an attitude verb or an Agent/Patient verb; and (3) the subject of the motion verb.

6.1.3. Procedure. Participants saw 4 items in each of 8 conditions, presented using a Latin Square design. Participants also saw the 24 filler and attention check items from Experiment 1, for a total of 56 items. Afterwards, participants answered demographic and bot check questions.

6.2. REgRESSION ANALYSIS. Two pre-registered mixed-effects logistic regression models were fitted to the response data. The first included three fixed effects, Perspective, Subjecthood, and Attitude, and their interactions, while the second treated Subjecthood and Attitude as nested within Perspective. Both used sum contrast coding and the maximal random effects structure.

6.3. RESUlTS. Experiment 3 replicated the subjecthood effect observed in the prior two experiments, but did not find a reliable effect of topicality or of type of subjecthood.

Figure 8 shows the participant means by condition. Within each of the four narrative conditions, the rate of come selection is consistently higher for the character who is the subject of the second sentence. This supports the subjecthood effect observed in the previous experiments. As Table 6 shows, the interaction between subjecthood and Perspective was significant $(p<0.00001)$, as were the nested effects of subjecthood for both Person A and B ( $p<0.00001$ each).

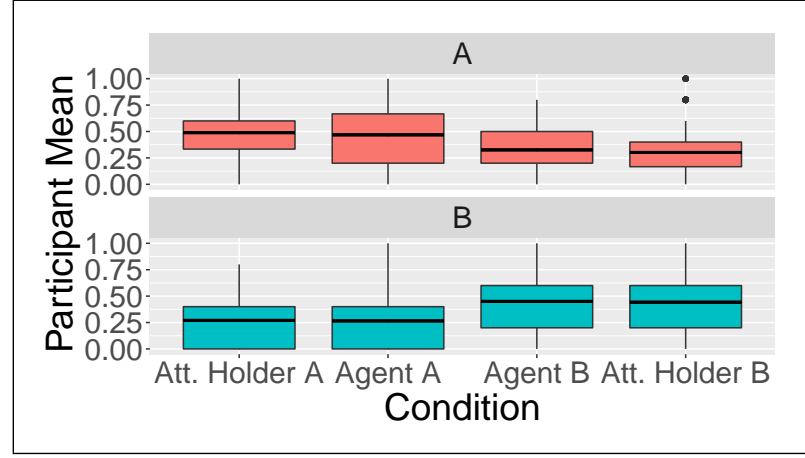

Figure 8: Experiment 3 means by condition

\begin{tabular}{|llll|}
\hline Persp. & A & B & come $[95 \%$ CI $]$ \\
\hline A & AP & Ob & $33 \%[30 ; 35]$ \\
& & Sub & $47 \%[44 ; 50]$ \\
& Attitude & Ob & $30 \%[28 ; 33]$ \\
& & Sub & $49 \%[47 ; 51]$ \\
\hline B & A/P & Ob & $27 \%[24 ; 29]$ \\
& & Sub & $45 \%[43 ; 47]$ \\
& Attitude & Ob & $27 \%[25 ; 29]$ \\
& & Sub & $44 \%[42 ; 47]$ \\
\hline
\end{tabular}

Table 5: Experiment 3 mean rate of come selection

However, the effect of relation to the theme observed in Experiment 2 did not replicate. Although the means for Person A conditions were higher in each pair of equivalent conditions (for instance, comparing the Person A Agent means with the Person B Agent means), the difference is slight, and as Table 5 shows, the confidence intervals largely overlap. The main effect of Perspective was not significant in the mixed-effects model $(p=0.1)$.

Manipulating the syntactic environment in the second sentence did not have a reliable effect: while the rate of come selection was slightly higher in the attitude verb condition when Person A was the subject and perspective holder, it was lower when Person B was the subject and perspective holder. No significant effect was found in either mixed-effects model (Table 6).

6.4. DisCUSSION. The results of Experiment 3 partially replicate the findings of the previous two experiments: they support an effect of subjecthood on perspective prominence, but not of relation 


\begin{tabular}{|llll|}
\hline Fixed effect $(n=3200)$ & $\widehat{\beta}$ & $z$ & $p$ \\
\hline Intercept $)$ & $-0.63(+/-0.12)$ & -5.1 & $<\mathbf{0 . 0 0 0 0 1}$ \\
A Perspective & $0.1(+/-0.07)$ & 1.6 & 0.1 \\
A Subject & $-0.03(+/-0.05)$ & -0.6 & 0.55 \\
Attitude & $-0.003(+/-0.04)$ & -0.06 & 0.9 \\
A Perspective*Subject & $0.44(+/-0.05)$ & 9.3 & $<\mathbf{0 . 0 0 0 0 1}$ \\
A Perspective*Attitudes & $-0.005(+/-0.04)$ & -0.1 & 0.9 \\
\hline (Intercept) & $-0.64(+/-0.13)$ & -5.1 & $<\mathbf{0 . 0 0 0 0 1}$ \\
A Perspective & $0.1(+/-0.07)$ & 1.5 & 0.14 \\
AxA Subject & $0.43(+/-0.08)$ & 5.2 & $<\mathbf{0 . 0 0 0 0 1}$ \\
BxA Subject & $-0.47(+/-0.07)$ & -6.3 & $<\mathbf{0 . 0 0 0 0 1}$ \\
AxAttitude & $-0.007(+/-0.06)$ & -0.1 & 0.91 \\
BxAttitude & $0.002(+/-0.06)$ & 0.04 & 0.97 \\
\hline
\end{tabular}

Table 6: Experiment 3 regression analyses, interaction (top) and nested (bottom) models

to the theme. They also do not provide insight into the effect of subjecthood: although attitude reports were predicted to strengthen the effect of subjecthood, no reliable effect was observed.

7. Conclusion. I have presented three experiments exploring the discourse factors that affect the prominence of perspective holders for perspectival motion verbs in American English. The results suggest that both local and global prominence play a role. Experiment 1 provided evidence that topicality and subjecthood increase the accessibility of characters' perspectives for come. Both of these effects were replicated in subsequent experiments.

However, the experiments exploring the source of these effects were less successful. While Experiment 2 found two topicality effects, mention order and relation to theme, the latter did not replicate in Experiment 3. Experiment 3 also explored two kinds of subject environments, attitude verbs and Agent/Patient verbs, but found no reliable difference between them.

The experimental data presented here contribute to the growing body of work exploring how perspective prominence is determined. It supports a view that although certain characters have global prominence by virtue of their topicality, others can become temporarily more prominent because of features of the syntactic environments in which they appear.

Although these findings are consistent with those from work on other perspectival expressions (Kaiser \& Lee 2017a, Hinterwimmer 2019), there remain many open questions about how consistent the observed effects are across classes of perspectival expressions. Because perspective prominence is a discourse-level phenomena, we might expect the same perspective ranking to be utilized across classes of expressions. On the other hand, if some of the attested effects spring from the semantics of individual expressions, as Kaiser \& Lee (2017a) suggest, then perspective prominence might not generalize across classes of perspective-sensitivity.

\section{References}

Banfield, Ann. 1982. Unspeakable Sentences: Narration and Representation in the Language of Fiction. London: Routledge. https: / / doi .org/10.4324/9781315746609. 
Barlew, Jefferson. 2017. The semantics and pragmatics of perspectival expressions in English and Bulu: The case of deictic motion verbs. Columbus, Ohio: The Ohio State University dissertation.

Bylinina, Lisa. 2014. The grammar of standards. Utrecht: LOT Dissertation Series.

Chafe, Wallace. 1976. Givenness, contrastiveness, definiteness, subjects, and topics. In Charles Li (ed.), Subject and Topic, 25-76. New York: Academic Press.

Charnavel, Isabelle. 2018. Deictic Perspective and Logophoric Exemption from Condition A. In William G. Bennett, Lindsay Hracs \& Dennis Ryan Storoshenko (eds.), West Coast Conference on Formal Linguistics, vol. 35, 124-131. Somerville, MA: Cascadilla Proceedings Project.

Charnavel, Isabelle. 2020. Logophoricity and Locality: a View from French Anaphors. Linguistic Inquiry 51(4). 671-723.

Eckardt, Regine. 2014. The Semantics of Free Indirect Discourse: How Texts Allow Us to Mindread and Eavesdrop (Current Research in the Semantics / Pragmatics Interface 31). Boston: Brill. https://doi.org/10.1163/9789004266735.

Harris, Jesse A. 2012. Processing Perspectives. Amherst, MA: University of Massachusetts, Amherst dissertation. https://scholarworks.umass.edu/dissertations/ AAI 3498347.

Harris, Jesse A. \& Christopher Potts. 2009. Perspective-shifting with appositives and expressives. Linguistics and Philosophy 36(2). 523-552. https://doi.org/10.1007/s10988-010-9070-5.

Heusinger, Klaus von \& Petra B. Schumacher. 2019. Discourse prominence: definition and application. Journal of Pragmatics 154.117-127. https://doi.org/10.1016/j. pragma.2019.07.025.

Hinterwimmer, Stefan. 2019. Prominent protagonists. Journal of Pragmatics 154. 79-91. https://doi.org/10.1016/j.pragma.2017.12.003.

Hobbs, Jerry R. 1979. Coherence and Coreference. Cognitive Science 3(1). 67-90. https://doi.org/10.1207/s15516709 $\operatorname{cog} 0301_{4}$.

Kaiser, Elsi. 2015. Perspective-shifting and free indirect discourse: Experimental investigations. In Sarah D’Antonio, Mary Moroney \& Carol Rose Little (eds.), Semantics and Linguistic Theory, vol. 25, 346-372. https://doi.org/10.3765/salt.v25i0.3436.

Kaiser, Elsi. 2020. Shifty behavior: Investigating predicates of personal taste and perspectival anaphora. In Joseph Rhyne, Kaelyn Lamp, Nicole Dreier \& Nicole Kwon (eds.), Semantics and Linguistic Theory, vol. 30, in press. https://doi.org/10.3765/salt.v30i0.4850.

Kaiser, Elsi \& Jamie Herron Lee. 2017a. Experience matters: A psycholinguistic investigation of predicates of personal taste. In Dan Burgdorf, Jacob Collard, Sireemas Maspong \& Brynhildur Stefánsdóttir (eds.), Semantics and Linguistic Theory, vol. 27, 323-339. https://doi.org/10.3765/salt.v27i0.4151.

Kaiser, Elsi \& Jamie Herron Lee. 2017b. Predicates of personal taste and multidimensional adjectives: An experimental investigation. In William G. Bennett, Lindsay Hracs \& Dennis Ryan Storoshenko (eds.), West Coast Conference on Formal Linguistics, vol. 35, 224-231. Somerville, MA: Cascadilla Proceedings Project.

Kehler, Andrew. 2002. Coherence, reference, and the theory of grammar. Stanford: CSLI Publi- 
cations.

Kehler, Andrew, Laura Kertz, Hannah Rohde \& Jeffrey L. Elman. 2008. Coherence and Coreference Revisited. Journal of Semantics 25(1). 1-44. https://doi.org/10.1093/jos/ffm018.

Kehler, Andrew \& Hannah Rohde. 2013. A Probabilistic Reconciliation of Coherence-Driven and Centering-Driven Theories of Pronoun Interpretation. Theoretical Linguistics 39(1-2). 1-37. https://doi.org/10.1515/tl-2013-0001.

Korotkova, Natalia. 2016. Heterogeneity and uniformity in the evidential domain. Los Angeles, CA: UCLA dissertation. https: / / escholarship.org/uc/item/40m5f2f1.

McNally, Louise \& Isidora Stojanovic. 2017. Aesthetic adjectives. In James Young (ed.), The Semantics of Aesthetic Judgments, 17-37. Oxford: Oxford University Press. $10.1093 /$ acprof : oso/9780198714590.001.0001.

Meuser, Sara, Stefan Hinterwimmer \& Maximilian Hörl. 2020. Online Processing of Protagonists' Perspective-Taking. In The CUNY Sentence Processing Conference, vol. 33, online.

Nakazawa, Tsuneko. 2007. A typology of the ground of deictic motion verbs as path-conflating verbs: the speaker, addressee, and beyond. Poznan Studies in Contemporary Linguistics 43(2). https://doi.org/10.2478/v10010-007-0014-3.

Nishigauchi, Taisuke. 2014. Reflexive binding: awareness and empathy from a syntactic point of view. Journal of East Asian Linguistics 23. 157-206. https://doi.org/10.1007/s10831-0139110-6.

Oshima, David. 2006a. GO and COME revisited: What serves as a reference point? In Zhenya Antić, Charles B. Chang, Emily Cibelli, Jisup Hong, Michael J. Houser, Clare S. Sandy, Maziar Toosarvandani \& Yao Yao (eds.), Proceedings of the Berkeley Linguistics Society, vol. 32, 287-298. Berkeley Linguistics Society. https://doi.org/10.3765/bls.v32i1.3466.

Oshima, David. 2006b. Motion deixis, indexicality, and presupposition. In Masayuki Gibson \& Jonathan Howell (eds.), Proceedings of Semantics and Linguistic Theory, vol. 16, 172-189. https://doi.org/10.3765/salt.v16i0.2942.

Pearson, Hazel. 2013. A Judge-Free Semantics for Predicates of Personal Taste. Journal of Semantics 30. 103-154. https://doi.org/10.1093/jos/ffs001.

Poesio, Massimo, Rosemary Stevenson, Barbara Di Eugenio \& Janet Hitzeman. 2004. Centering: A Parametric Theory and Its Instantiations. Computational Linguistics 30(3). 309-363. 10.1162/0891201041850911.

Roberts, Craige. 2020. Character study: A de se semantics for indexicals. Ms. New York University.

Sudo, Yasutada. 2018. Come vs. Go and Perspective Shift. Ms. Rutgers University.

Sundaresan, Sandhya. 2018. Perspective is syntactic: evidence from anaphora. Glossa 3(1)(128). 1-40. http://doi.org/10.5334/gjgl.81. 